\title{
BIOCHEMICAL ACTIVITIES OF LACTOSE-DERIVED PREBIOTICS - A REVIEW
}

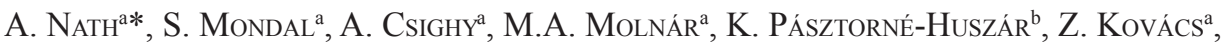 \\ A. KORIS ${ }^{\mathrm{a}}$ and Gy. VATAI ${ }^{\text {a* }}$ \\ ${ }^{a}$ Department of Food Engineering, Faculty of Food Science, Szent István University, H-1118 Budapest, Ménesi út \\ 44. Hungary \\ ${ }^{\mathrm{b}}$ Department of Refrigeration and Livestock Product Technology, Faculty of Food Science, Szent István \\ University, H-1118 Budapest, Ménesi út 43-45. Hungary
}

(Received: 2 December 2016; accepted: 27 March 2017)

\begin{abstract}
In the dairy industry different types of prebiotics, such galacto-oligosaccharide, lactulose, lactosucrose, tagatose, lactitol, lactobiono- and glucono- $\delta$-lactone are synthesized through different chemical and biochemical reactions (hydrolysis, transgalactosylation, isomerization, fructosyl-transfer, reduction, and oxidation) as well as microbial fermentation processes using raw whey or isolated lactose as feedstock. Lactose-derived prebiotics have several functional and nutritional values. The biochemical activities of lactose-based prebiotics are expressed in the presence of probiotics (lactic acid bacteria, yeasts, Bacillus spp.). Galacto-oligosaccharide and lactosucrose reduce the risk of bowel disorder (diarrhea), inflammatory bowel disease (ulcerative colitis and crohn's disease), and colon cancer. Galacto-oligosaccharide helps colonic absorption of minerals (iron, magnesium and calcium) and prevents osteoporosis. Lactulose, galacto-oligosaccharide, and lactitol promote laxative activity. Furthermore, lactulose may decrease the risk of hepatic encephalopathy. Prebiotics have low calorific value and glycemic index. Galactooligosaccharide and tagatose reduce the risks of hyperglycemia (Type 2 diabetes) and low density lipid (lipoprotein) accumulation in blood stream. Moreover, prebiotics improve immunomodulation, which reduces the risk of respiratory infection and allergies. This review describes unique biochemical mechanisms of several types of lactose-derived prebiotics.
\end{abstract}

Keywords: lactose-derived prebiotics, probiotics, biochemical activities, health benefit

The major by-product of dairy industry is whey, which comprises $80-90 \%$ of the total volume of milk entering the process of cheese production (PRAZERES et al., 2012). From a long prior, liquid whey or isolated pure lactose have been used for the synthesis of different prebiotics, such as galacto-oligosaccharide, lactulose, lactosucrose, tagatose, lactitol, lactobiono- and glucono- $\delta$-lactone through different chemical and biochemical reactions, such as hydrolysis, transgalactosylation, isomerization, fructosyl-transfer, reduction, and oxidation. In many cases microbial fermentation processes have been adopted for lactose-based prebiotics synthesis (StYevkó et al., 2013; NATH et al., 2016). They have unique functional and nutritional values (Fig. 1). In the present review unique biochemical activities and mechanism of actions of several types of lactose-based prebiotics are reported. The articles with keywords lactose,

\footnotetext{
* To whom correspondence should be addressed

Phone: +3613057112; fax: +3613057323, e-mails: Vatai.Gyula@etk.szie.hu, arijit0410@gmail.com
}

This is an open-access article distributed under the terms of the Creative Commons Attribution 4.0 License, which permits unrestricted use, distribution, and reproduction in any medium for non-commercial purposes, provided the original author and source are credited. 
prebiotics, biological activity, prebiotic-probiotic interaction, and human health benefit have been searched judiciously in the Web of Science and information are summarized from the articles, published in 1992-2016.

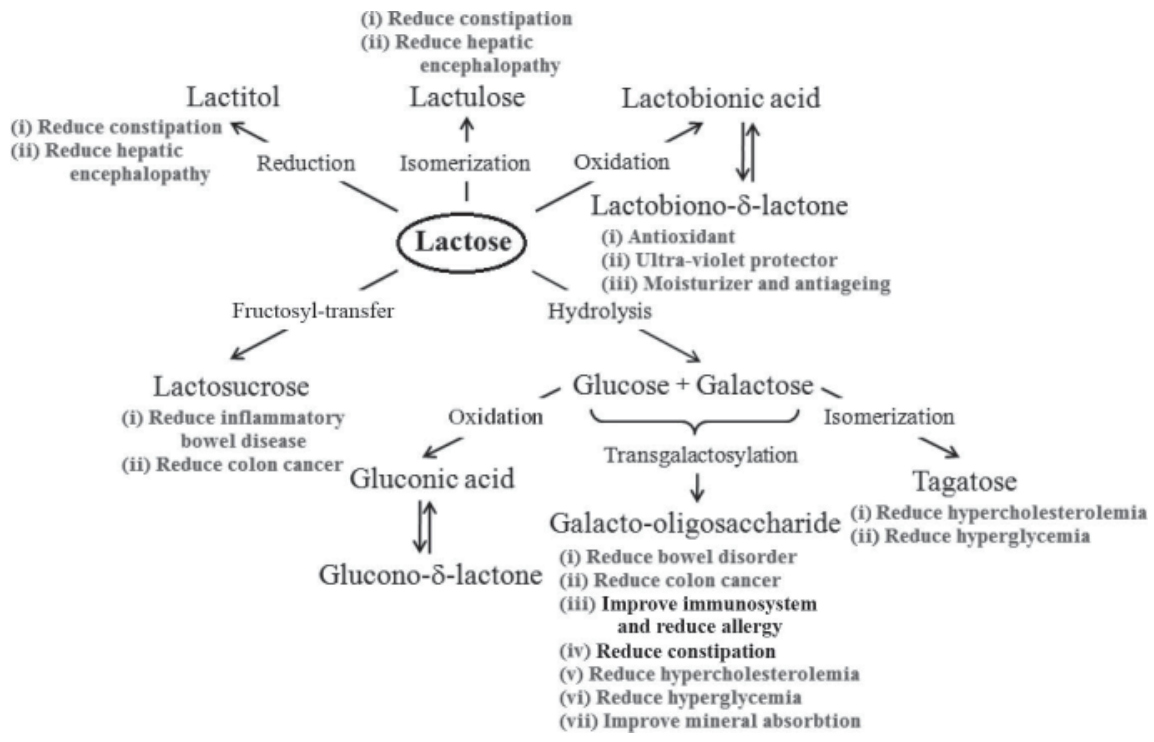

Fig. 1. Different functional and nutritional values of lactose-derived prebiotics (figure compiled by the authors based on NAGPAL and co-workers, 2012 and NATH and co-workers, 2016).

\section{Functional and biological activities of lactose-based prebiotics}

The criteria of a prebiotic are determined by its resistance to upper tract of gut enzymes, no absorption through the gastrointestinal tract, stable during food processing, broken down by intestinal microbiota (probiotics), and the selective stimulation of growth and/or activity of probiotics (WANG, 2009). Probiotics Lactobacillus spp. reside mainly in the small intestine, while Bifidobacterium spp. are generally present in the large intestine. They are able to survive in gastric acidity, antibiotics, lysozyme, and other hostile conditions in the gastrointestinal tract. The biological activities of lactose-based prebiotics are expressed in the presence of probiotics. The interactions between prebiotics and probiotics can reduce several health problems as well as promote sustainable health (NAGPAL et al., 2012). Probiotics have the potential to break down prebiotics in the gastrointestinal tract due to their unique gene construction. The rate of fermentation of the individual prebiotic depends on the carbohydrate monomer, glycosidic linkage, degree of polymerisation, interaction with gut bacteria, fermentation mechanism, and saccharolytic capacity of the probiotic (GOH \& KLAENHAMMER, 2015).

\subsection{Inhibition of bowel disorder and inflammatory bowel disease}

Prebiotics galacto-oligosaccharide and lactosucrose can prevent the colonization of the gastrointestinal tract by pathogens and reduce the risks of several bowel disorders (antibiotic 
associated diarrhea, traveler's diarrhea, acute watery diarrhea, Clostridium difficile associated relapsing diarrhea), and inflammatory bowel diseases (Crohn's disease and ulcerative colitis). There are different biochemical actions regarding the inhibition mechanisms of pathogens by probiotics in the presence of prebiotics (SzEkÉr et al., 2007; AurELI et al., 2011). The mechanisms include (a) competitive exclusion of pathogens (antiadhesion effect) by probiotics, (b) synthesis of bacteriocins by probiotics, (c) biotransformation of the prebiotic into lactic acid and short chain fatty acids (acetic acid, propanoic acid, and butyric acid), (d) competition for nutrients among pathogens and probiotics, (e) development of immunomodulation, and (f) synthesis of antigens (this mechanism proceeds via production of cytokines, such as Interleukin-10, which inhibit the T-helper 1, T-helper 2, T-helper 7 and T-helper 17, and transforming growth factor- $\beta$, which produces immunoglobulin A) (Oelschlaeger, 2010). The mechanisms are represented in Figure 2.

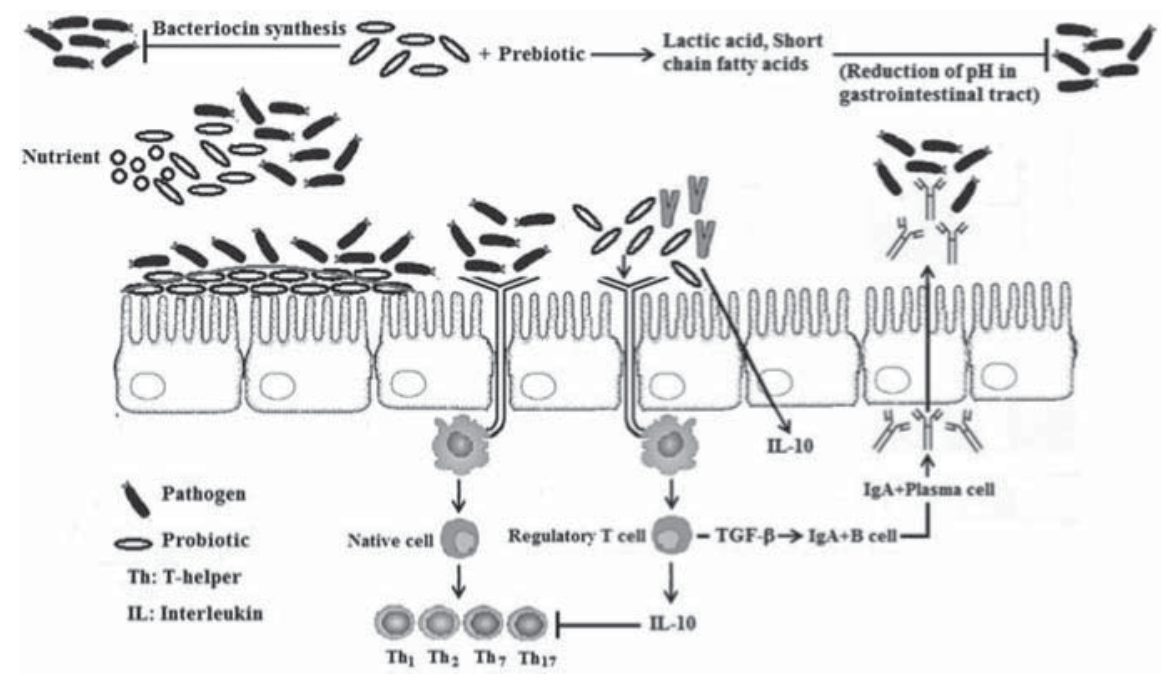

Fig. 2. Mechanisms of inhibition of pathogens by probiotics (figure compiled by the authors based on KHALIGHI and co-workers, 2016)

\subsection{Reduction of hepatic encephalopathy}

Typically, prebiotic lactulose is considered for treatment of hepatic encephalopathy, caused by accumulation of the toxic bacterial metabolites (ammonia) in blood stream due to liver damage. There are three suggested mechanisms through which prebiotic lactulose reduces the risk of hepatic encephalopathy; (1) a decrease in total ammonia in the portal blood by (a) decreasing bacterial urease activity, (b) decreasing ammonia absorption by decreasing $\mathrm{pH}$, (c) improving the nutritional status of gut epithelium, (d) decreasing intestinal permeability; (2) a decrease in oxidative stress and inflammation in the hepatocytes, leading to an increased hepatic clearance of toxins and ammonia; and (3) a decrease in the uptake of other toxins (Solga, 2003). Lactulose is broken down into short chain fatty acids as well as hydrogen and carbon dioxide by probiotic bacteria (Bifidobacterium spp. and Lactobacillus spp.) in the lower gut. Substantial hydrogen and carbon dioxide in the lower gut cause a rapid intestinal 
hurry and thus massive amounts of colonic microorganisms, such as urease-positive bacteria and deaminating bacteria are removed. As a result, intestinal uptake of the toxic bacterial metabolites, e.g. ammonia, is reduced (BONGAERTS et al., 2005).

\subsection{Reduction of risk of colon cancer}

It has long been reported that certain bacterial metabolites in the large intestine are associated with negative effects on the host cell and could lead to initiation and/or proliferation of colon carcinogenesis. In particular, bacterial synthesized enzymes, such as $\beta$-glucuronidase, $\beta$-glucosidase, azoreductase, and nitroreductase are associated with the appearance of colon carcinogens (KumAr et al., 2015). Lactose-derived pebiotics are broken down by gut probiotics and converted into different short chain fatty acids, which reduce the $\mathrm{pH}$ of the colon. At lower $\mathrm{pH}$, pathogenic bacteria cannot survive in the intestine. Also, due to antiadhesion effect of lactose-based prebiotics, competition for nutrients, and negative influence of probiotic synthesized bacteriocins, the undesirable colonic microorganism are hindered. As a result, production and activities of genotoxic enzymes are impeded, and risk of appearance of colon cancer is reduced (Bugaut \& BentésaC, 1993). Prebiotic-derived butyric acid is revealed as a potential inhibitor of growth and inducer of phenotype differentiation and apoptosis. It also reduces risk factors of colon cancer and tumor development (WolLowsKi et al., 2001). Butyrate and acetate are able to alter the geneexpression in tumor cells and reduce the induction of DNA damage (HAGUE et al., 1995; MARCHETTI et al., 1997). In colon cells, glutathione transferase Pi is the most abundant, and it is an important enzyme involved in the detoxification of both electrophilic products and compounds associated with oxidative stress. The synthesis of enzyme glutathione transferase Pi in colon cells is increased by butyrate (CsORDAs, 1995; TREPTOW-vAN LishaUt et al., 1999). It has been reported that butyrate is the major source of energy for colonocytes, which helps to maintain a healthy epithelium and to an extent prevents cancer (Topping \& CLIFTON, 2001).

\subsection{Improvement of mineral absorption}

It was reported that prebiotic galacto-oligosaccharide plays a crucial role in the colonic absorption of minerals; particularly calcium, magnesium, and iron, which are responsible for developing bone structure, preventing osteoporosis and cell development (ScHOlz-AHrens et al., 2007). Probiotics ferment galacto-oligosaccharide in the intestine and produce short chain fatty acids, so guts become acidic. Inorganic salts, such as iron, magnesium, and calcium salts are insoluble at a neutral $\mathrm{pH}$. The acidification of the intestine makes the calcium (Chonan et al., 1995, 1996; van DEN Heuvel et al., 1998), magnesium (Chonan et al., 1996), and iron (VAN DEN Heuvel et al., 1998) salts soluble, which leads to their increased absorption in the intestine.

\subsection{Controlling blood lipids}

Lactose-based prebiotics, such as galacto-oligosaccharide (VuLEvIC et al., 2013) and tagatose (Police et al., 2009) play a crucial role in lipid regulation, although the exact mechanism is still unclear. Few possible mechanisms are (1) the deconjugation of bile acids through bile salt hydrolase catalysis, (2) the capture and assimilation of cholesterol for stabilization of their cell membranes, (3) binding cholesterol to the cell membrane of probiotics in the gastrointestinal tract, (4) conversion of cholesterol into coprostanol, and (5) inhibition of 
hepatic cholesterol synthesis by short chain fatty acids produced by probiotic bacteria and/or redistribution of cholesterol from plasma to the liver (HomAYOunI et al., 2012).

\subsection{Controlling blood glucose level}

It has been reported that lactose-based prebiotics, such as galacto-oligosaccharide (SANGWAN et al., 2015) and tagatose (ENSOR et al., 2015), reduce the long-standing elevated level of blood glucose (hyperglycemia). Several possible mechanisms have been published. In the intestine, lactose-derived prebiotics are transformed to short chain fatty acids by probiotics. It has been reported that short chain fatty acids may affect plasma glucose levels by increasing the gut hormones GLP-1 and PYY, via activation of the receptors Ffar3 and Ffar2 (KELLOW et al., 2014; Kasubuchi et al., 2015). Lactose derived prebiotics promote the growth of probiotics, those offer anti-diabetic effects against insulin resistance and inflammation by increasing liver natural killer $\mathrm{T}$ cells, modulating tumor necrosis factor- $\alpha$ expression and reducing nuclear factor- $\kappa \mathrm{B}$ binding activity (MA et al., 2008). Furthermore, probiotics may improve glucose metabolism by delaying or inhibiting the intestinal absorption of glucose, increasing the bioavailability of gliclazide (AL-SALAMI et al., 2008) and altering the activity of autonomic nervous system (YAMANO et al., 2006).

\subsection{Improvement of immune system}

Lactose-based prebiotics play a crucial positive role in the development of immune system, both before vaccination and as adjuvant in vaccines. Prebiotics in the presence of probotics regulate both systemic and mucosal immunities. Interactions of prebiotics and probiotics can modulate the activities of different cells of the immune system, such as natural killer cells, dendritic cells, macrophages, granulocytes, epithelial cells, as well as adaptive system T-helper 1, T-helper 17, regulatory T cells, T lymphocytes, and B lymphocytes (KLAENHAMmer et al., 2012; HARDY et al., 2013). It is well documented that prebiotic galacto-oligosaccharide is broken down by probiotic bifidobacteria, lactobacilli and short chain fatty acids are synthesized. Butyric acid suppresses the lymphocyte proliferation, inhibits cytokine production from T-helper 1-lymphocytes, and upregulates interleukin-10 production. It also suppresses the expression of the transcription factor such as nuclear factor- $\kappa \mathrm{B}$ and upregulates Toll-like receptors expression (Hoyles \& Vulevic, 2008; Амiт-Romach et al., 2010). It has been reported that the symbiotic effect of probiotic and galacto-oligosaccharide reduces the risk of immunoglobulin E-associated allergies, such as eczema (dermatitis), allergic rhinitis, or asthma. Beside that, lactose-derived prebiotics reduce the risk of respiratory infections (otitis media, sinusitis, bronchitis, and pneumonia) (BRUZZESE et al., 2009).

\subsection{Anti-constipation}

For a long time, prebiotic lactulose has been popularly used for the treatment of constipation (Theresa \& Pettit-Young, 1992). Lactulose and other disaccharides (example: lactitol) are broken down by probiotics, and different types of short chain fatty acids are synthesized, the gut becomes more acidic, leading to a reduction of ammonia absorption in mucosa. The presence of ammonia in the gut causes water to be drawn into the lower intestine, which increases the amount of water in stool, softening and making it pass more easily, reducing the transit time of constipated subjects (SCHUMANN, 2002). 


\subsection{Low caloric value}

Lactose-based prebiotics have low calorific value and are beneficial to everybody regardless of age or gender. Lactose-derived prebiotics are resistant to salivary degradation as well as the digestion of pancreatic enzymes and gastric juices. Therefore, they offer lower glycemic index values and a calorific value 50\% lower than sucrose. Cummings and co-workers (1997) reported that calorific value of galacto-oligosaccharide is $1-2 \mathrm{kcal} \mathrm{g}^{-1}$. According to the Japanese standard method, the calorific value of galacto-oligosaccharide was $1.73 \mathrm{kcal} \mathrm{g}^{-1}$ (SchaAfsma, 2008).

\section{Conclusions}

Different types of lactose-derived prebiotics are synthesized through different chemical and biochemical reactions and microbial fermentation processes. In the present review, several biochemical actions of different types of lactose-derived prebiotics are described. However, while more promising potential health effects of prebiotics are being summarized in the current article, there are many biochemical outcomes of probiotic and prebiotic interactions that are still unclear. Therefore, more investigations in this area are prerequisite. It is hoped that this review will receive the attention of medical practitioners, food and nutrition research communities, and will open a new area in the field of waste valorization.

The first author acknowledges the Hungarian State Board Post doctoral Research Fellowship, Hungary and the EU project 'FP7 - PEOPLE - 2012-CIG - Marie Curie Action: Career Integration Grants'.

\section{References}

Al-Salami, H., Butt, G., Tucker, I., Skrbic, R., Golocorbin-Kon, S. \& Mikov, M. (2008): Probiotic pre-treatment reduces gliclazide permeation (ex vivo) in healthy rats but increases it in diabetic rats to the level seen in untreated healthy rats. Arch. Drug Inform., 1, 35-41.

Amit-Romach, E., Uni, Z. \& Reifen, R. (2010): Multistep mechanism of probiotic bacterium, the effect on innate immune system. Mol. Nutr. Food Res., 54, 277-284.

Aureli, P., Capurso, L., Castellazzi, A.M., Clerici, M., Giovannini, M., Morelli, L., Poli, A., Pregliasco, F., Salvini, F. \& Zuccotti, G.V. (2011): Probiotics and health: An evidence-based review. Pharmacol. Res., 63, 366-376.

Bongaerts, G., Severijnen, R. \& Timmerman, H. (2005): Effect of antibiotics, prebiotics and probiotics in treatment for hepatic encephalopathy. Med. Hypotheses, 64, 64-68.

Bruzzese, E., Volpicelli, M., Squeglia, V., Bruzzese, D., Salvini, F., Bisceglia, M., Lionetti, P., Cinquetti, M., Iacono, G., Amarri, S. \& Guarino, A. (2009): A formula containing galacto- and fructo-oligosaccharides prevents intestinal and extra-intestinal infections: An observational study. Clin. Nutr., 28, 156-161.

Bugaut, M. \& BentéJac, M. (1993): Biological effects of short-chain fatty acids in nonruminant mammals. Annu. Rev. Nutr., 13, 217-241.

Chonan, O., Matsumoto, K. \& Watanuki, M. (1995): Effect of galactooligosaccharides on calcium absorption and preventing bone loss in ovariectomized rats. Biosci. Biotech. Biochem., 59, 236-239.

Chonan, O., Takahashi, R., Yasui, H. \& Watanuki, M. (1996): Effects of beta 1-4 linked galactooligosaccharides on use of magnesium and calcification of the kidney and heart in rats fed excess dietary phosphorous and calcium. Biosci. Biotech. Biochem., 60, 1735-1737.

Csordas, A. (1995): Toxicology of butyrate and short-chain fatty acids. -in: HiLl, M.J. (Ed.), Role of gut bacteria in human toxicology and pharmacology. Taylor and Francis, London, pp. 105-127. 
Cummings, J.H., Roberfroid, M.B., Anderson, H., Barth, C., Ferro-Luzzi, A., Ghoos, Y., Gibney, M., Hermonsen, K., James, W.P.T., Korver, O., Lairon, D., Pascal, G. \& Voragen, A.G.S. (1997): PASSCLAIM - Gut health and immunity. Eur. J. Clin. Nutr., 51, 417-423.

Ensor, M., Banfield, A.B., Smith, R.R., Williams, J. \& Lodder, R.A. (2015): Safety and efficacy of D-tagatose in glycemic control in subjects with type 2 diabetes. J. Endocrinol. Diabetes Obes., 3, 1-24.

Goh, Y.J. \& Klaenhammer, T.R. (2015): Genetic mechanisms of prebiotic oligosaccharide metabolism in probiotic microbes. Annu. Rev. Food Sci. Technol., 6, 137-156.

Hague, A., Elder, D.J.E., Hicks, D.J. \& Pareskeva, C. (1995): Apoptosis in colorectal tumour cells: induction by the short chain fatty acids butyrate, propionate and acetate and by the bile salt deoxycholate. Int. J. Cancer, 60, 400-406.

Hardy, H., Harris, J., Lyon, E., Beal, J. \& Foey, A.D. (2013): Probiotics, prebiotics and immunomodulation of gut mucosal defences: Homeostasis and immunopathology. Nutrients, 5, 1869-1912.

Homayouni, A., Payahoo, L. \& Azizi, A. (2012): Effects of probiotics on lipid profile: A review. Am. J. Food Technol., 7, 251-265

Hoyles, L. \& Vulevic, J. (2008): GI microbiota and regulation of the immune system. -in: HufFnagle, G.B. \& Noverr, M.C. (Eds) Advances in experimental medicine and biology. Landes Biosciences, Texas, pp. 79-92.

Kasubuchi, M., Hasegawa, S., Hiramatsu, T., Ichimura, A. \& Kimura, I. (2015): Dietary gut microbial metabolites, short-chain fatty acids, and host metabolic regulation. Nutrients, 7, 2839-2849.

Kellow, N.J., Coughlan, M.T., Savige, G.S. \& Reid, C.M. (2014): Effect of dietary prebiotic supplementation on advanced glycation, insulin resistance and inflammatory biomarkers in adults with pre-diabetes: a study protocol for a double-blind placebo-controlled randomised crossover clinical trial. BMC Endocrine Disorders, $14,55$.

Khalighi, A., Behdani, R. \& Kouhestan, S. (2016): Probiotics: A comprehensive review of their classification, mode of action and role in human nutrition. -in: RaO, V. \& RaO, L.G. (Eds) Probiotics and prebiotics in human nutrition and health. INTECH Publication, Croatia, pp. 19-39.

Klaenhammer, T.R., Kleerebezem, M., Kopp, M.V. \& Rescigno, M. (2012): The impact of probiotics and prebiotics on the immune system. Nat. Rev. Immunol., 12, 728-734.

Kumar, K.S., Sastry, N., Polaki, H. \& Mishra, V. (2015): Colon cancer prevention through probiotics: An overview. J. Cancer Sci. Ther., 7, 81-92.

Ma, X., HuA, J. \& Li, Z. (2008): Probiotics improve high fat diet-induced hepatic steatosis and insulin resistance by increasing hepatic NKT cells. J. Hepatol., 49, 821-830.

Marchetti, C., Migliorati, G. \& Moraca, R. (1997): Deoxycholic acid and SCFA-induced apoptosis in the human tumor cell-line HT-29 and possible mechanisms. Cancer Lett., 114, 97-99.

Nagpal, R., Kumar, A., Kumar, M., Behare, P.V., Jain, S. \& Yadav, H. (2012): Probiotics, their health benefits and applications for developing healthier foods: A review. FEMS Microbiol. Lett., 334, 1-15.

Nath, A., Verasztó, B., Basak, S., Koris, A., Kovács, Z. \& Vatai, G. (2016): Synthesis of lactose-derived nutraceuticals from dairy waste whey - A review. Food Bioprocess Tech., 9, 16-48.

Oelschlaeger, T.A. (2010): Mechanisms of probiotic actions - A review. Int. J. Med. Microbiol., 300, $57-62$.

Police, S.B., Harris, J.C., Lodder, R.A. \& CAssis, L.A. (2009): Effect of diets containing sucrose vs. D-tagatose in hypercholesterolemic mice. Obesity (Silver Spring), 17, 269-275.

Prazeres, A.R., Carvalho, F. \& Rivas, J. (2012): Cheese whey management: A review. J. Environ. Manage., 110, $48-68$.

SAngwan, V., Tomar, S.K., Ali, B., Singh, R.R. \& Singh, A.K. (2015): Hypoglycaemic effect of galactooligosaccharides in alloxan-induced diabetic rats. J. Dairy Res., 82, 70-77.

SchaAfsma, G. (2008): Lactose and lactose derivatives as bioactive ingredients in human nutrition. Int. Dairy J., 18, $458-465$.

Scholz-Ahrens, K.E., Ade, P., Marten, B., Weber, P., Timm, W., Açıl, Y., Glüer, C.C. \& Schrezenmeir, J. (2007): Prebiotics, probiotics, and synbiotics affect mineral absorption, bone mineral content, and bone structure. J. Nutr., 137, 838S-846S.

Schumann, C. (2002): Medical, nutritional and technological properties of lactulose. An update. Eur. J. Nutr., 41, $17-25$.

Solga, S.F. (2003): Probiotics can treat hepatic encephalopathy. Med. Hypotheses, 61, 307-313.

Styevkó, G., Styevkó, Cs., Hoschke, Á. \& Nguyen, Q.D. (2013): Oligosaccharide synthesized by glycosyltransferase activity from Pectinex Ultra SP-L enzyme preparation. Acta Alimentaria, 42, 99-106.

Szekér, K., Németh, E., Kun, Sz., Beczner, J. \& Gálfi, P. (2007): Adhesion of lactic acid bacteria to Caco-2 cells - Evaluation of different detection methods. Acta Alimentaria 36, 365-371. 
Theresa, V.K. \& Pettit-Young, N.A. (1992): Lactulose in the management of constipation: A current review. Ann. Pharmacother., 26, 1277-1282.

Topping, D.L. \& Clifton, P.M. (2001): Short-chain fatty acids and human colonic function: Roles of resistant starch and nonstarch polysaccharides. Physiol. Rev., 81, 1031-1064.

Treptow-van Lishaut, S., Rechkemmer, G., Rowland, I.R., Dolara, P. \& Pool-Zobel, B.L. (1999): The carbohydrate crystalean and colonic microflora modulate expression of glutathione S-transferase subunits in colon of rats. Eur. J. Nutr., 38, 76-83.

van den Heuvel, E.G.H.M., Schaafsma, G., Muys, T. \& van Dokkum, W. (1998): Non-digestible oligosaccharides do not interfere with calcium and nonheme-iron absorption in young, healthy men. Am. J. Clin. Nutr., 67, $445-451$.

Vulevic, J., Juric, A., Tzortzis, G. \& Gibson, G.R. (2013): A mixture of trans-galactooligosaccharides reduces markers of metabolic syndrome and modulates the fecal microbiota and immune function of overweight adults. J. Nutr., 143, 324-331.

WAng, Y. (2009): Prebiotics: Present and future in food science and technology. Food Res. Int., 42, 8-12.

Wollowski, I., Rechkemmer, G. \& Pool-Zobel, B.L. (2001): Protective role of probiotics and prebiotics in colon cancer. Am. J. Clin. Nutr., 73, 451-455.

Yamano, T., Tanida, M., Nitjma, A., Maeda, K., Okumura, N. \& Fukushima, Y. (2006): Effects of the probiotic strain Lactobacillus johnsonii strain La1 on autonomic nerves and blood glucose in rats. Life Sci., 79, 19631967. 